\title{
ФАКТОР ВЛИЯНИЯ ПАНДЕМИИ COVID-19 НА МИРОВОЙ ТУРИЗМ
}

\section{FACTOR OF THE INFLUENCE \\ OF THE COVID-19 PANDEMIC ON WORLD TOURISM}

I. Donskikh

Summary. In the past year, many articles have been written on the impact of the COVID-19 pandemic on the travel industry. Finding out how the tourism, travel and hospitality industry will recover from the COVID-19 pandemic and how to make the industry resilient in a dramatically changed world is critical today. In less than six months, COVID-19 has proven to be a far more serious pandemic than any other. Such a severe crisis in the tourism business has not been observed since the Second World War. However, any crisis leads not only to negative consequences, but also opens up prospects for further research.

Keywords: COVID-19, vaccination, coronavirus, pandemic, tourism, tourism industry.

и ндустрия туризма - до пандемии COVID-19, была одной из движущих сил мировой экономики в эпоху глобализации. По данным Всемирной туристской организации (ЮНВТО), в 2019 году вклад туризма в мировой ВВП составил 10,3\% (8,9 трлн. долларов (ША). На индустрию туризма приходилось $28,3 \%$ мирового экспорта услуг и 4,3\% от общего объема экспорта. Доля туризма в мировой торговле составляла 7 процентов. Кроме того, каждое десятое рабочее место в мире приходилось на индустрию туризма и обеспечивало средствами к существованию миллионы людей в развитых и развивающихся странах через сложную производственно-сбытовую цепочку взаимосвязанных отраслей. В 2019 году в туристическом секторе было занято 330 миллионов человек. Это была третья по величине экспортная отрасль в мировой экономике [14].

Туризм - это динамичный сектор, на который влияют внутренние и внешние социально-экономические факторы, которые происходят как последствия основных глобальных трансформаций и потрясений (среди прочего, стихийные бедствия, пандемии здравоохранения, экономические кризисы, терроризм и технологический прогресс) и другие глубокие изменения в обществе. Преобразования, происходящие в настоящее время в мире, безусловно, будут иметь последствия для туристического сектора.

\author{
Донских Иван Сергеевич \\ Аспирант, Гродненский государственный \\ университет имени Янки Купалы \\ ivan_danskikh@tut.by
}

Аннотация. В последний год было написано множество статей о влиянии пандемии COVID-19 на туристическую индустрию. Сегодня очень важно выяснить, как индустрия туризма, путешествий и гостеприимства восстановится после пандемии COVID-19 и как сделать отрасль устойчивой в резко изменившемся мире. Уже менее чем за шесть месяцев COVID-19 оказался гораздо более серьезной пандемией, чем любая другая. Такого тяжелого кризиса в туристском бизнесе не наблюдалось со времен Второй мировой войны. Однако любой кризис ведет не только к негативным последствиям, но и открывает перспективы для дальнейших исследований.

Ключевые слова: COVID-19, вакцинация, коронавирус, пандемия, туризм, туристическая индустрия.

В этом смысле туризм является одним из секторов, наиболее пострадавших от пандемии COVID-19, серьезно влияя на экономику, средства к существованию людей, общественные услуги и существенно ограничивая возможности развития региона. В то же время восстановление туристической активности открывает перспективы для исследований.

В 2019 году число международных туристских прибытий достигло 1,5 миллиарда, что на 4\% больше, чем в 2018 году, что было кульминацией десятилетия, в течение которого туризм рос быстрее, чем мировая экономика в целом.

Несмотря на рост, важно отметить, что мировой туризм в прошлом подвергался широкому спектру кризисов. В период с 2000 по 2015 год к числу серьезных разрушительных событий относятся террористические атаки 11 сентября 2001 г., вспышка тяжелого острого респираторного синдрома (SARS) 2003 г., глобальный экономический кризис, разразившийся в 2008/2009 гг. и вспышка ближневосточного респираторного синдрома 2015 г. (MERS) [20].

Примечательно, что пандемия коронавируса, разразившаяся в Китае в декабре 2019 года, нанесла туристической отрасли несоизмеримо больший ущерб, чем 
теракты 11 сентября 2001 года. После 11 сентября количество поездок впервые упало на 0,6\%. с 1982 года. Кризис затронул такие регионы, как Америка $(-6,0 \%)$, Южная Азия $(-4,5 \%)$, Ближний Восток $(-2,5 \%)$ и Европа $(-0,7 \%)$, в то время как остальные регионы продолжали демонстрировать устойчивый рост: Африка на 4,3\% и регион Восточной Азии и Тихого океана на 5,5\% [16].

Гёсслинг, Скотт и Холл в своей работе отмечают, что ни один из кризисов, до пандемии коронавируса, не привел к долгосрочному снижению глобального развития туризма. Только SARS $(-0,4 \%)$ и глобальный экономический кризис $(-4,0 \%)$ привели к снижению в прибытии из-за рубежа [20]. Это говорит о том, что туризм как система устойчив к внешним потрясениям. Однако есть много свидетельств того, что последствия пандемии COVID-19 будут беспрецедентными. [8].

Дополняя их точку зрения Чанг, МакАлир и Рамос пишут, что важно различать уникальную пандемию, такую как COVID-19, которая может продолжаться в обозримом будущем и другие события мирового масштаба, упомянутые выше. COVID-19 с его долгосрочным воздействием на международное сообщество, экономическую и финансовую среду навсегда изменил мир во всех мыслимых отношениях и сильно повлиял на него для всех людей в каждой отрасли, включая международные путешествия, туристический спрос и индустрию гостеприимства [6].

Соглашаясь с указанными авторами Зелински и Ботеро также утверждают, что индустрия туризма в прошлом переживала различные разрушительные события, ни одно из которых не имело долгосрочное негативное влияние на туризм [22].

Большинство стран ввели различные уровни изоляции, которые включали в себя карантинные меры и социальное дистанцирование. Применение этих мер варьировалось от мягкого подхода, принятого Швецией, до полной изоляции, введенной в Индии. Чем суровее ограничения, тем выше потери рабочих мест и банкротства предприятий. Такие меры, естественно, влияют на экономику каждой страны, и этот эффект измеряется сокращением ВВП [9]. Ограничительные меры, в той или иной степени, применяются до сих пор во многих странах.

Этот кризис стал большим потрясением для развитых стран и чрезвычайной ситуацией для наиболее обездоленных людей и территорий. Туризм остановился в середине марта 2020 года. Только за первые месяцы года число международных туристских прибытий сократилось на 56\%, а в мае 2020 - на $98 \%$. Это привело к потере почти 320 миллиардов долларов от экспорта, что более чем в три раза превышает потери во время всего мирового экономического кризиса 2009 года. По итогу 2020 года ЮНВТО зафиксировало сокращение международных туристических прибытий на 70-75\%. Сокращение числа туристов в мире было тотальным, так как ограничительные меры были введены правительствами большинства стран. Потеря доходов от международного туризма составила 1,1 триллиона долларов США. Расчетные потери в глобальном ВВП составили более двух триллионов долларов США. Таким образом уровень международного туризма упал до уровня показателей 1990-х годов [15].

Даже в отдельных туристических дестинациях, где до недавних пор наблюдались чрезмерные туристские потоки и там, где наблюдалась ситуация сверхтуризма и туризмофобии, было зафиксировано полное исчезновение турпотоков. Свертывание туристической деятельности в мире привело к существенным экономическим потерям сокращению доходов населения, бюджетов государств и муниципалитетов, значительному увеличению безработных [4].

Карантин перевёл основную часть жизни человека в зону домашнего пребывания, снизился спрос на услуги, связанные с туризмом, такие как посещение различных заведений, значительно сократились статьи расхода, связанные с передвижением, питанием вне дома, приобретением одежды и т.д. Запрет на проведение массовых мероприятий оказал влияние на сферу развлечений.

Распространение COVID-19 и связанных с ним запретов на поездки и передвижение проникли практически во все аспекты повседневной жизни. Эти ограничения также угрожают нанести ущерб индустрии туризма и гостеприимства; услуги по размещению сократились, рестораны закрываются [17].

Таким образом внутри стран вирус затронул практически все звенья цепочки создания стоимости в сфере гостеприимства. Гёсслинг, Скотт и Холл утверждают, что, в отличие от других секторов бизнеса, доходы от туризма теряются безвозвратно, потому что непроданные мощности - например, в сфере размещения - не могут быть проданы в последующие годы, что имеет соответствующие последствия для занятости в этом секторе [8].

Текущие прогнозы ЮНВTO в отношении COVID-19 показывают, что на восстановление уровня международных туристических прибытий 2019 года мировой туристической отрасли потребуется от двух до четырех лет в зависимости от степени распространения пандемии и продолжительности ограничений, напрямую влияющих на туристический сектор. По прогнозам Всемирной туристской организации на 2021-2024 гг. по- 
следствия пандемии могут поставить под угрозу от 100 до 120 миллионов прямых рабочих мест в туристическом секторе. Ситуация особенно критическая, поскольку около 80\% туристических компаний являются микро-, малыми и средними предприятиями [15].

Помимо прочего на людей в течение долгого времени воздействует окружающая среда страха, беспокойства и незащищенности, и они привыкают оставаться на месте и отказываться от поездок. Эта тенденция еще больше увеличивает время восстановления туристической индустрии [13].

Как отмечают в своей работе Симонян и Сарян, в разгар кризиса даваемые прогнозы развития туризма на перспективу не могут отличаться требуемой достоверностью. При этом необходимо брать во внимание, что сам кризис включает две составляющие: экономическую и медицинскую, которые являются факторами, влияющими на эти прогнозы. На первоначальном этапе экономическая и медицинская составляющие кризиса были тесно взаимосвязаны между собой как фактор и следствие. В дальнейшем характер их взаимодействия начинает становиться равноценным: развитие пандемии влияет на экономическое состояние государства или на отдельные его регионы и наоборот: экономические возможности и резервы государства позволяют ему эффективно бороться с пандемией и оказывать помощь в этой борьбе [4].

Эпидемии и пандемии - две самые пугающие новости для путешественников и специалистов по планированию туризма. В таких случаях избежать заболевания может быть сложно или невозможно. Кроме того, риску подвергаются не только путешественники, но и другие люди, с которыми они контактируют во время путешествия. Пассажиры играют серьезную роль в передаче эпидемий или пандемий между туристскими дестинациями [13].

Другое важное значение COVID-19 можно найти в социокультурной сфере. Пандемия привела к напряженности, поскольку появилась антикитайская риторика, основанная на Китае как месте происхождения и распространения вируса. Позже туризмофобия стала также распространяться и на туристов из других стран т.к. именно туристы сыграли основную роль в стремительном распространении коронавируса. Для многих туристических направлений по всему миру желанию туристов вернуться сюда противостоит страх перед потенциальной передачей вируса от туристов, который испытывают местные жители [22].

Сейчас многие исследователи задаются вопросом: как будет выглядеть туристическая индустрия и весь мир после пандемии [11]?
Хайвуд считает, что внутреннему туризму суждено доминировать на начальных этапах восстановления, поскольку подавляющее большинство туристов, вероятно, будут приезжать из близлежащих районов. Также правительства регулярно напоминают туристам, чтобы те были очень избирательными в отношении туристических направлений и количества поездок, которые они совершают [10].

Логунцова также считает, что первым ожидаемо будет восстанавливаться внутренний туризм. Однако, вероятнее всего, покупательская способность населения снизится, поэтому возрастет спрос на бюджетные туры по собственным странам. Помимо этого Логунцова отмечает, что к моменту окончания пандемии и открытия границ между странами в индустрии туризма накопится огромный отложенный спрос [3].

По версии Симонян и Сарян также эффектом этого длительного восстановления отрасли является формирование отложенного спроса после преодоления коронавирусного кризиса [4].

Из-за введения ограничительных мер, касающихся предоставления услуг в области общественного питания и других мест проведения досуга, было сокращено большое количество менеджеров, официантов, продавцов, барменов и др. Это способствует росту количества безработных, готовых работать за невысокую плату, что позволит поднять экономику с наименьшими затратами [1].

Как показывает мировой опыт, кризисы не только неизбежны, но и в определенном смысле необходимы, поскольку они связаны не только с негативными явлениями и процессами - кризисы почти всегда открывают дополнительные возможности для дальнейшего роста и развития [3].

В числе этих возможностей и вызовов - ускорение процессов цифровизации туристских сервисов, более активное внедрение современных технологий (например, больших данных, искусственного интеллекта, смешанной и дополненной реальности и т.п.). Кроме того, ожидаемо усилится важность такого фактора, как безопасность путешествий (включая санитарно-эпидемиологическую обстановку места пребывания) [3].

Так, ограничения на передвижение в период кризиса создали условия для виртуального туризма. Закрытие музеев, театров и других мест посещения туристов в познавательных целях, удовлетворения эстетических и иных духовных потребностей, побудило малые и средние предприятия отрасли диверсифицировать свою деятельность и предложить туристам виртуальные онлайн-услуги [4]. 
Юнус, Масаго, Хидзиока, отразили в своей работе, что уровень загрязняющих веществ значительно снизился, когда промышленность и судоходство были приостановлены. Карантинные мероприятия положительно сказались на качестве пляжей и природных туристических дестинаций [21].

Уверенность в безлопастных поездках и отсутствия рисков для потенциального туриста повлияют на скорость восстановления отрасли. В долгосрочной перспективе туризм, скорее всего, вернется к докризисным показателям. Однако туристы могут уделять больше внимания гигиене при выборе жилья [5].

Постепенное восстановление туризма началось в 2021 году одновременно с началом вакцинации. Разработка вакцин - важный инструмент в борьбе с инфекционными заболеваниями [12].

Однако в долгосрочной перспективе ожидается, что восстановление будет медленным, и в процессе восстановления многие компании не смогут выжить. Замедление экономического роста также будет препятствовать быстрому восстановлению спроса на туризм, поскольку это скажется на расходах на отдых многих семей. Хотя туризм в большинстве стран не является основной движущей силой экономики, на него в значительной степени полагаются некоторые регионы [22].

Государственные органы должны тесно сотрудничать со средствами массовой информации, чтобы делиться знаниями и укреплять доверие граждан [22], чтобы уменьшить страх населения перед вакцинацией. Поскольку чем больше процент вакцинированных, тем быстрее восстановится туризм.

Гибкость и маневренность - две важнейшие характеристики, необходимые туристической индустрии. Ожидается, что в будущем потребность в мобильности, потреблении и свободе останется высокой, но ее отражение будет формировать ее в зависимости от местного контекста. Наряду с усилиями по нормализации ситуации, туристический сектор должен обеспечить путешественникам уверенность в отношении рисков. По мнению коллектива авторов Скаре, Сориано и Порада-Рочо, чтобы турфирмы могли работать с полной надежностью и гибкостью, требуются обновления политики страхования путешествий, возмещения и изменения плана [13].

Учитывая масштабы воздействия коронавируса на сферу туризма и гостеприимства, необходимы совместные, междисциплинарные исследовательские проекты, которые будут иметь решающее значение для того, чтобы позволить экспертам в области медицины и здравоохранения, а также специалистам в области туризма и гостеприимства собраться вместе и применить соответствующие знания для восстановления индустрии туризма после COVID-19. Это поможет защитить здоровье и благополучие различных заинтересованных сторон в сфере туризма, от путешественников до сотрудников сферы туризма [17].

Всемирная туристская организация подготовила свои рекомендации по смягчению социально-экономического воздействия пандемии на сферу туризма в различных странах. Рекомендации подразумевают под собой смягчение последствий пандемии и стимулирование ускоренного восстановления индустрии туризма путем сохранения рабочих мест; поддержки ликвидности компаний; пересмотр налогов и сборов, связанных с индустрией туризма; стимулирование инвестиций в туризм; обеспечение подготовки туристов к путешествиям, связанной в том числе с имеющимся уровнем риска пандемий; диверсификация рынков, продуктов и сервисов и др. [3].

Среди прочих нововведений, которые привнес коронавирус в туристическую индустрию, стоит выделить так называемый - Вакцинный туризм, который по мнению ряда экспертов, может стать одним из трендов медицинского туризма. Его суть заключается в организации внутренних или международных поездок групп и отдельных туристов с целью вакцинации [2].

На сентябрь 2021 года в мире вакцину от COVID-19 получили около 33\% населения, однако распределение вакцин было неравномерным, поскольку большая часть вакцин отправляется в самые богатые страны. Еще до начала вакцинации развитые страны зарезервировали больше половины всех будущих вакцин от коронавируса. Наименее привитым континентом на сегодняшний день является Африка. [2]

В европейском туризме важно обратить внимание на организационные новшества, связанные с распространением COVID-19. 9 июня 2021 г. Европарламент утвердил введение ковид-сертификатов, еще известных как «ковид паспорта», которые упростят процедуру пересечения границ. Большинство депутатов Европарламента поддержало правила, требуя от всех стран ЕС вводить и принимать бесплатные свидетельства вакцинации, отрицательном результате тестирования. Данные правила гарантируют, что гражданам Европы будут бесплатно выдаваться цифровые или бумажные сертификаты, что позволит им путешествовать в другие страны ЕС без дополнительных усилий. Сертификаты доступны полностью вакцинированным людям, обладателям свежих ПЦР или тестов с отрицательным результатом, а также людям, которые перенесли болезнь в течение последних шести месяцев. Страны принима- 
ют все вакцины, одобренные Европейским агентством по лекарственным средствам (ЕМА).

Данное новшество является барьером для потенциальных туристов из стран, где нет возможности привиться вакцинами, одобренными Европейским агентством по лекарственным средствам (EMA). Но вместе с этим это создает стимулы для Вакцинного туризма.

В целом стоит отметить, что проекты вакцинных туров трудно реализуемы. Существует избыточное количество препятствий, не позволяющих им стать массовыми и рентабельными [2].

В то же время ряд экспертов настаивает на том, что тема вакцин от коронавируса политизирована. Производителей вдохновляют перспективы миллиардных прибылей, а государствам чрезвычайно важно продемонстрировать преимущество своей системы здравоохранения и вакцинирования [2].

Ковид паспорта было предложено рассматривать их как альтернативу введению строгих ограничительных мер общественного здравоохранения или разрешению неограниченного распространения инфекции. Таким образом, был сделан выбор в пользу «наименее ограничительной альтернативы» [18].

У исследования есть два основных ограничения, которые связаны с тем, что пандемия COVID-19 по-прежнему является недавним явлением, и объем соответствующих исследований, хотя и быстро растет, все еще ограничен. Следовательно, результаты ограниченного числа исследований могут не быть окончательными, и можно ожидать противоречивых результатов будущих исследований [22].

Постоянный анализ данных важен из-за неопределенности, связанной с COVID-19 и возникающие колебания спроса в ответ на краткосрочные изменения из-за новостей о смертях и ограничительных мероприятий. Хотя туристическому направлению удавалось восстанавливаться после пандемий в прошлом, новые условия COVID-19 не означают, что прошлый опыт является хорошим индикатором будущих результатов [7].

\section{ЛИТЕРАТУРА}

1. Аблаев Р.Р., Шемякина В.П., Курило А.В. Тенденции развития мировой экономики в условиях социальных ограничений, связанных с пандемией COVID-19 [Электронный ресурс] // StudNet. 2021. № 1. URL: https://cyberleninka.ru/article/n/tendentsii-razvitiya-mirovoy-ekonomiki-v-usloviyahsotsialnyh-ogranicheniy-svyazannyh-s-pandemiey-covid-19 (дата обращения: 20.09.2021).

2. Горошко Н.В., Пацала С.В., Емельянова Е.К. «Вакцинный туризм» эпохи COVID-19: реальность или иллюзия для России [Электронный ресурс] // Социальные аспекты здоровья населения. 2021. № 3. URL: https://cyberleninka.ru/article/n/vaktsinnyy-turizm-epohi-covid-19-realnost-ili-illyuziya-dlya-rossii (дата обращения: 20.09.2021).

3. Логунцова И.В. Индустрия туризма в условиях пандемии коронавируса: вызовы и перспективы [Электронный ресурс] // Государственное управление. Электронный вестник. 2020. № 80. URL: https://cyberleninka.ru/article/n/industriya-turizma-v-usloviyah-pandemii-koronavirusa-vyzovy-i-perspektivy (дата обращения: 20.09.2021).

4. Симонян Г.А., Сарян А.А. 0 влиянии пандемии коронавируса на туризм [Электронный ресурс] // Современная научная мысль. 2020. № 2. URL: https:// cyberleninka.ru/article/n/o-vliyanii-pandemii-koronavirusa-na-turizm (дата обращения: 20.09.2021).

5. Assaf A., Scuderi R. COVID-19 and the recovery of the tourism industry. Tourism Economics. 2020;26(5):731-733. doi:10.1177/1354816620933712

6. Chang C.L., McAleer M, Ramos V.A Charter for Sustainable Tourism after COVID-19. Sustainability. 2020; 12(9):3671. https://doi.org/10.3390/su12093671

7. Gallego I., Font X. Changes in air passenger demand as a result of the COVID-19 crisis: using Big Data to inform tourism policy, Journal of Sustainable Tourism. 2021 29:9, 1470-1489, doi: 10.1080/09669582.2020.1773476

8. Gössling S., Scott D., Hall M. Pandemics, tourism and global change: a rapid assessment of COVID-19, Journal of Sustainable Tourism. 2021 29:1, 1-20, D0I: 10.1080/09669582.2020.1758708

9. Grech V., Grech P., Fabri S. A risk balancing act — Tourism competition using health leverage in the COVID-19 era. Int J Risk Saf Med. 2020;31(3):121-130. doi: 10.3233/JRS-200042. PMID: 32597822.

10. Haywood K. A post COVID-19 future — tourism re-imagined and re-enabled, Tourism Geographies. 2020 22:3, 599-609, doi: 10.1080/14616688.2020.1762120

11. Joseph M. Cheer Human flourishing, tourism transformation and COVID-19: a conceptual touchstone, Tourism Geographies. 2020 22:3, 514-524, doi: 10.1080/14616688.2020.1765016

12. Prideaux B., Thompson M., Pabel A. Lessons from COVID-19 can prepare global tourism for the economic transformation needed to combat climate change, Tourism Geographies. 2020 22:3, 667-678, D0I: 10.1080/14616688.2020.1762117

13. Ugur N., Akbiyik A. Impacts of COVID-19 on global tourism industry: A cross-regional comparison. Tourism management perspectives. 202036.100744. 10.1016/j.tmp.2020.100744.

14. UNWTO Policy Brief: COVID-19 and Transforming Tourism, august 2020 Edition. — Madrid: UNWT0. — 27 p.

15. UNWTO Policy Brief: COVID-19 and Tourism 2020: A year in review december 2020 Edition. — Madrid: UNWT0. — $10 \mathrm{p}$. 
16. UNWTO Tourism Highlights, 2002 Edition. — Madrid: UNWTO, 2002. - $7 \mathrm{p}$.

17. Wen J., Wang W., Kozak M, Liu X., Hou H. Many brains are better than one: the importance of interdisciplinary studies on COVID-19 in and beyond tourism, Tourism Recreation Research. 2021 46:2, 310-313, D0I: 10.1080/02508281.2020.1761120

18. Wilf-Miron R., Myers V., Saban M. Incentivizing Vaccination Uptake: The "Green Pass" Proposal in Israel. JAMA. 2021;325(15):1503-1504. doi:10.1001/ jama. 2021.4300

19. Williams C.C. Impacts of the coronavirus pandemic on Europe's tourism industry: Addressing tourism enterprises and workers in the undeclared economy. Int J Tourism Res. 2021; 23: 79-88. https://doi.org/10.1002/jtr.2395

20. World Bank International tourism, number of arrivals. Retrieved April 4, 2020 [Electronic resource]. — Access mode: https://data.worldbank.org/indicator/ ST.INT.ARVL

21. Yunus A.P., Masago Y., Hijioka Y. COVID-19 and surface water quality: Improved lake water quality during the lockdown. Sci Total Environ. 2020 Aug 20;731:139012. doi: 10.1016/j.scitotenv.2020.139012. Epub 2020 Apr 27. PMID: 32388159; PMCID: PMC7185006.

22. Zielinski S., Botero C.M. Beach Tourism in Times of COVID-19 Pandemic: Critical Issues, Knowledge Gaps and Research Opportunities. International Journal of Environmental Research and Public Health. 2020; 17(19):7288. https://doi.org/10.3390/ijerph17197288

(c) Донских Иван Сергеевич ( ivan_danskikh@tut.by ).

Журнал «Современная наука: актуальные проблемы теории и практики»

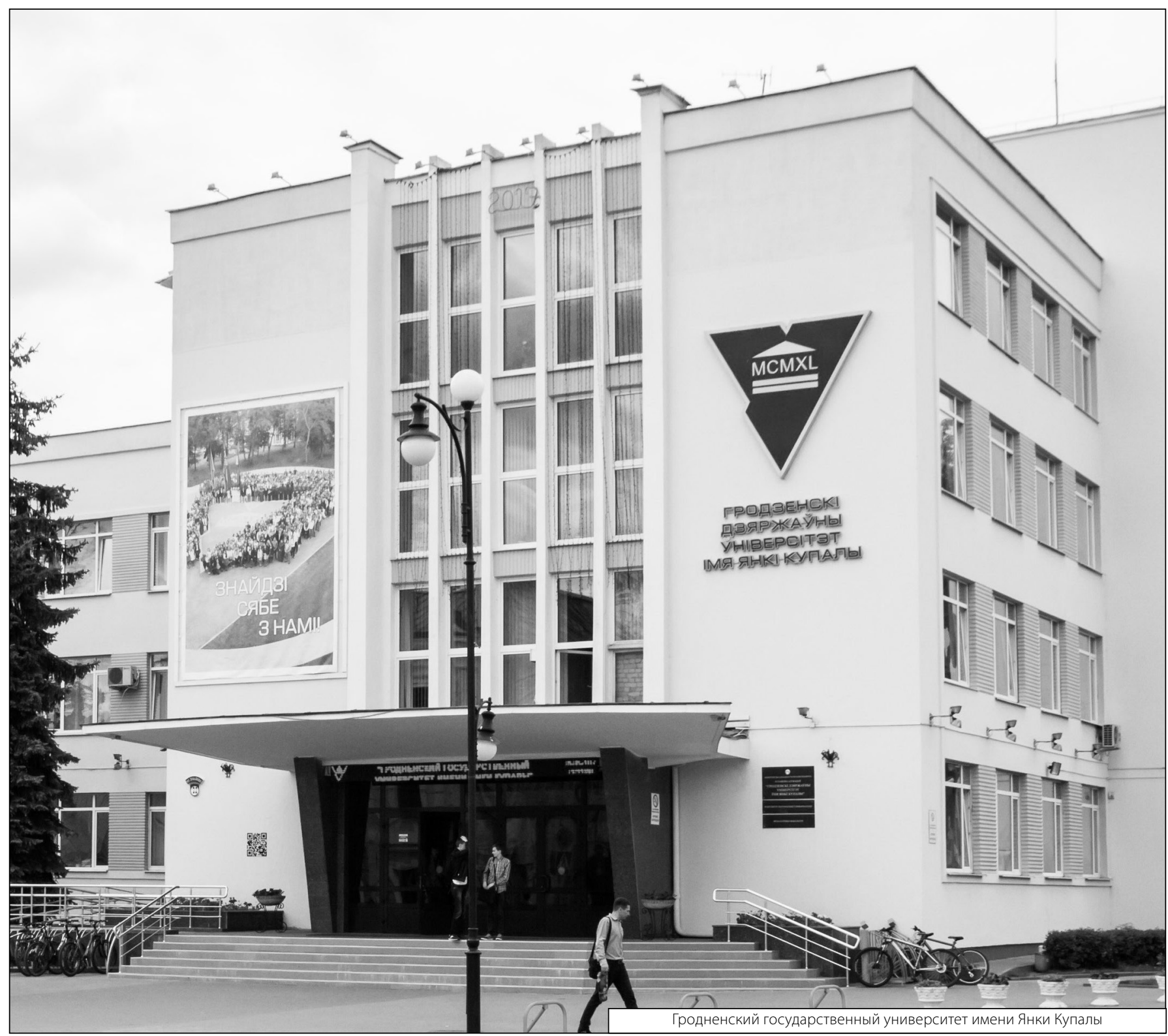

